\title{
The end of life experience of older adults in Ireland
}

Peter May ${ }^{1}$, Christine McGarrigle ${ }^{2}$, Charles Normand ${ }^{1}$

1. Centre for Health Policy and Management, Trinity College Dublin, Ireland

2. The Irish Longitudinal Study on Ageing

On behalf of the TILDA team

October 2017 
Copyright (C) The Irish Longitudinal Study on Ageing 2017

The Irish Longitudinal Study on Ageing

Lincoln Place

Trinity College Dublin

Dublin 2

Tel: +35318962509

Email: tilda@tcd.ie

Website: www.tilda.ie

https://www.doi.org/10.38018/TildaRe.2017-05 


\section{Key Findings}

This is the first TILDA topic report examining the end-of-life experience of older adults in Ireland. Using interviews completed by family members and friends, the report examines how people died (place and cause of death, health and serious events at end of life), which services and care they received (from both the formal healthcare system and from their families and friends), and factors associated with end-of-life patterns and experiences.

This report is based on data from 375 completed end-of-life interviews, representing $73 \%$ of 516 confirmed deaths among TILDA participants between Wave 1 (2009) and Wave 3 (2014) of the study. 160 participants for whom an interview was completed died between Wave 1 and Wave 2 (2012), and 215 died between Wave 2 and Wave 3. The average age of death among participants for whom an interview was completed was 78 years and $54 \%$ of participants were male. Nearly half $(46 \%)$ of participant deaths occurred in hospital. Other places included their own home (27\%), a hospice $(11 \%)$ and a nursing home $(10 \%)$.

The main findings are as follows:

- There was wide variation in disability among older adults in the last three months of life. Approximately a third were disability-free while another third needed help with most everyday tasks such as eating, bathing and taking medications.

- As well as a high prevalence of non-modifiable conditions such as serious chronic illness, significant proportions of older people experienced health problems towards the end of life that can be modified to improve quality of life, including falls $(41 \%)$, regular pain $(50 \%)$ and regular depression (45\%).

- Healthcare utilisation increases in the last year of life but there is no pattern of highly intensive end-of-life care that is sometimes observed in other countries and is often associated with poor end-of-life experience. On average participants visited the GP six times in the last year of life and experienced one hospital inpatient admission. A minority spent time in a hospice (12\%) and/or nursing homes (18\%). Many people accessed community care such as a public health nurse (45\%), allied health care such as physiotherapy (33\%) and home care services such as home help $(20 \%)$ in the last year of life. 
- Significant proportions of people who needed community care services were unable to access them. There is no evidence connecting this unmet need to socioeconomic or geographical factors. Rather, the data suggest that inability to access community care stems from lack of awareness of availability and a reluctance to apply for services.

- Help from friend-and-family networks, also known as informal care, comprised a substantial proportion of the care received by older people in the last three months of life. On average, people received two hours of care per day but $10 \%$ received 24 hour unpaid assistance. When the cost of informal care is estimated alongside formal healthcare costs in the last year of life, unpaid help from friend-and-family networks accounted for $42 \%$ of the total cost of care received.

- Average use of healthcare services and receipt of unpaid help from family and friends must be interpreted carefully as these cover important differences that exist by illness and disability burden. As expected, a minority of seriously ill older adults accounted for most of the end-of-life care received from both the formal health service and from friend-and-family networks in the last year of life.

- Receipt of formal and informal care in the last year of life was strongly associated with disability level and serious illness. However, other determinants were also evident:

- Older people who lived alone had different patterns of experience in the last year of life from those who lived with others. People who lived alone received less informal help with everyday activities, but this shortfall was not matched by increased use of formal healthcare services. People living alone therefore received less care on average.

- Those who lived in rural areas were less likely to die in a nursing home than those in urban areas.

- Those with heart disease or depression were more likely to have been unable to access services that they needed.

- Old age is itself not a driver of health service use in the last year of life. Rather, it is factors associated with age such as disability and serious chronic illness that increase health service use. However, old age is associated with receipt of significantly higher levels of informal care. 
The TILDA sample was carefully constructed to be representative of the population over 50 in Ireland in terms of socioeconomic conditions, geography and age (Kenny et al., 2010). However, it is important to note that only community-dwelling older people were recruited at the start of the study. It will take some time for the TILDA population at the end of life fully to match the wider population of older people near the end of life - the TILDA population is younger, less frail and with fewer long-term chronic conditions. As such, the patterns reported here should be interpreted with caution. 


\section{Preface}

The TILDA team wish to acknowledge the generosity of family members and friends who gave of their time and emotions to share with us the end-of-life experiences of loved ones. It is our hope that the information provided by this report will assist in planning better services for end of life in Ireland. As with all the TILDA research we have explicitly taken every precaution to ensure the anonymity of deceased participants and family and friends who helped with this research.

Thank you.

\section{Acknowledgements}

We would like to acknowledge the vision and commitment of our funders, Irish Life, The Atlantic Philanthropies and the Department of Health, which is providing funding on behalf of the state. We would also like to state that any views expressed in this report are not necessarily those of the Department of Health or of the Minister of Health. We would also like to thank the TILDA participants without whom this research would not be possible. 


\section{Contents}

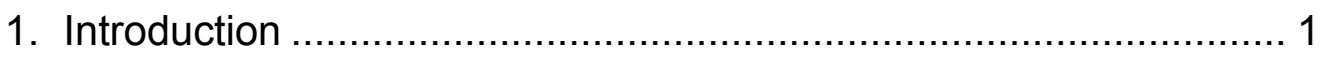

2. Description of TILDA participants at end of life ……….................. 5

3. Place and cause of death, and health at end of life ....................... 6

4. Health service use, and help from family and friends ................. 12

5. Key associations with end-of-life experience ............................. 19

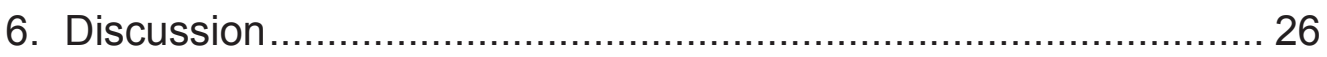

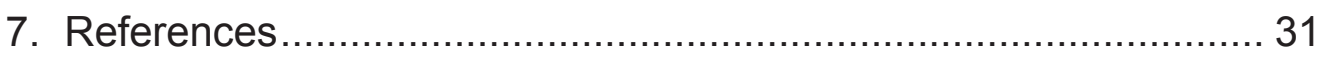




\section{Introduction}

The experience and healthcare service use of people at end of life is a global public health priority (Centeno et al., 2013, Institute of Medicine, 2014). International evidence shows that people with serious and life-limiting illnesses account for high proportions of healthcare budgets yet often have poor outcomes and fragmented care (Meier, 2011). A large majority of people would prefer to die at home (Gomes et al., 2012) yet studies consistently find up to half of deaths in high-income countries occur in an acute hospital (Bekelman et al., 2016). Death in hospital can be associated with inappropriate treatment, and poor patient and family experiences (Teno et al., 2013).

International studies of palliative and end-of-life care provision report Ireland as a strong performer by international standards (Economist Intelligence Unit, 2015, Centeno et al., 2013). However, many people do not use these services due to, for example, sudden death or lack of availability, and so for many people the end-of-life experience does not include support from palliative care. The Central Statistics Office publish summary population data on key measures such as cause of death and age at death (Central Statistics Office, 2017), but until recently there has been little detailed data on end-of-life experience for older people in Ireland at the population level (Kane et al., 2015, Brick et al., 2015). Interviews provided by the family members and friends of TILDA participants about the last year of life provides a valuable opportunity to examine needs in the last year of life, how much support was provided to meet these needs, place and experience of death in Ireland, and reasons why experiences vary.

\section{TILDA}

TILDA is a longitudinal study of ageing. Participants were recruited to form a representative sample from community-dwelling over 50 -year-olds in Ireland. They are followed up wherever they are living, using face-to-face interviews and self-reported questionnaires and health assessments.

The study is conducted in waves: participants completed an interview and health assessment at enrolment in Wave 1 between 2009 and 2010, and are then invited to a 
follow-up interview every two years and a health assessment every four years. 8,504 people took part in the first wave of TILDA, 7,610 in the second wave in 2012, and 6,566 in the third wave in 2014. A description of the original recruitment is available elsewhere (Barrett et al., 2011), and a series of reports on the data collected and analysed to date are also available (http://tilda.tcd.ie/publications/). TILDA is part of an international family of longitudinal ageing studies, including the Health and Retirement Survey (HRS) in the United States and the English Longitudinal Study on Ageing (ELSA), which employ similar methods, including end-of-life interviews, and record directly comparable data for crossnational analyses (Steptoe et al., 2013).

At Wave 2 and Wave 3, if follow-up confirmed that a TILDA participant had died, a family member or close friend was asked to complete a short interview to provide information about the final months of the participant's life and their end-of-life experience. This interview examines how people died (health, serious events and conditions, cause and place of death), and what services and care they received from both the formal healthcare system and from their families and friends in the last year of life. The information obtained during these interviews is used in this report, which is the first topic report examining the end-of-life experience of older adults in Ireland.

The end-of-life interview comprises eight topics:

- Demographics: demographic details (e.g. age, sex, marital status) and her/his death (e.g. cause, date, location).

- Disability and level of assistance: details of activities of daily living (ADL, e.g. dressing, bathing, getting into bed) and instrumental activities of daily living (IADL, e.g. cooking, shopping, managing money) in the last three months of life, and assistance received in performing these activities.

- Physical health: diagnoses of serious and chronic conditions (e.g. cardiovascular disease, cancer) and treatments (e.g. surgery, chemotherapy), and level of physical activity in last year of life.

- Behavioural health: prevalence of behaviours with important health implications such as smoking, alcohol intake and weight loss.

- Cognitive function: difficulties with memory and interpreting surroundings.

- Mood: level of contentment and prevalence of depression. 
- Healthcare utilisation: use of general practitioner (GP) and hospital services, home care services (e.g. home help, meals on wheels), and allied health and social care (e.g. dentist, physiotherapist) in the last year of life.

- Assets and insurance: details of a will and insurance policies.

This report does not review all data comprehensively but instead summarises and presents some of the most important findings.

\section{Sampling}

As TILDA is a nationally representative population study of people over 50 in Ireland who were community-dwelling on entry into the study, people living in residential settings including nursing homes and hospices in Wave 1 were not recruited, but people who transitioned into such settings were followed up in future waves. Thus, it is inevitable that in the early years of the study the TILDA sample is a little younger than Ireland's over-50 population overall, that there will be more sudden deaths and fewer people with longterm chronic conditions. However, these differences are already relatively small and are expected to diminish over time as the study matures.

Of the 516 participants in TILDA whose deaths have been confirmed between Waves 1 and 3, 375 (73\%) family members and friends completed the interview about the participant's end-of-life experience.

\section{Estimating formal and informal care costs}

For estimating costs, formal healthcare is defined as care received from the healthcare system including GP, emergency department, hospital inpatient and hospital outpatient visits; nursing home and hospice stays; and receipt of home care, community care and allied health care. Informal healthcare is defined as unpaid help received from family and friend networks in addressing difficulties in everyday living. The small amount of paid help from family and friends (e.g. through the Health Service Executive (HSE) carer allowance) was classified as formal care in this report, such that informal care reflects unpaid help only. The results reported here do not change substantively if paid help from family and friends is reclassified as informal care. Use of formal and informal healthcare services were costed using frequency data reported in the TILDA interviews and unit costs derived for a previous study in Ireland (Brick et al., 2015). 


\section{Associations between participant characteristics and end-of-life experience}

The majority of the analysis in this report is descriptive. However, in order to examine associations between particular outcomes and a variety of individual characteristics, multivariate regression is used. For a given outcome (e.g. place of death, cost of formal healthcare) we regressed the outcome against a fixed set of predictors potentially associated with end-of-life experience, including demographic factors (e.g. age, sex, location in Ireland), socioeconomic factors (e.g. education level, medical card status, private health insurance), and indicators of health and disabilities (e.g. (instrumental) activities of daily living; presence of serious health conditions such as cancer, heart disease and dementia). This allows us to ascertain the main drivers of particular outcomes, e.g., is age associated with healthcare costs once health and disability has been taken into account?

\section{Report Structure}

Chapter 2 describes the socio-demographic characteristics of the participants who died. Chapter 3 describes how people died, including place and cause of death, and health and disability in the last year of life. Chapter 4 analyses participants' use of formal healthcare services (e.g. GP, hospital, hospice, nursing home) in the last year of life as well as informal care provided by family and friends. The total cost of care of formal and informal care services in the last year of life is estimated. Chapter 5 reports the important associations between participant characteristics (e.g. demographics, socioeconomics, disability and health) and outcomes with important implications for end-of-life experience and health policy (e.g. place of death, use of services and unmet need, formal and informal care costs). Chapter 6 interprets these findings, places them in international context and considers policy implications. 


\section{Description of TILDA participants at end of life}

The socio-demographic characteristics of the TILDA participants who died, for whom an end-of-life interview was completed, are presented in Table 1.

The majority were male (54\%) with an average age at death of 77.7 years and a slight age differential by sex (women lived on average more than a year longer). More than $75 \%$ of those who died were over 70 years old.

Forty-four per cent of deceased participants were married and a further $38 \%$ widowed. Nearly one half of participants (47\%) were resident in rural areas, $23 \%$ were resident in Dublin and $29 \%$ in other towns and cities.

Table 1. Participant Characteristics $(n=375)$

\begin{tabular}{|c|c|c|c|}
\hline & & Mean & (Range) \\
\hline \multirow[t]{4}{*}{ Age } & All & 77.7 & $(71-86)$ \\
\hline & Male & 77.1 & $(71-85)$ \\
\hline & Female & 78.3 & $(71-87)$ \\
\hline & & $\%$ & (N) \\
\hline \multirow[t]{2}{*}{ Sex } & Male & 54 & (204) \\
\hline & Female & 46 & $(171)$ \\
\hline \multirow[t]{3}{*}{ Marital Status } & Married/cohabiting & 44 & $(166)$ \\
\hline & Divorced/seperated/never married & 17 & $(65)$ \\
\hline & Widowed & 38 & $(144)$ \\
\hline \multirow[t]{3}{*}{ Highest education achieved } & Primary/none & 54 & $(203)$ \\
\hline & Secondary & 30 & $(113)$ \\
\hline & Tertiary/higher & 15 & $(57)$ \\
\hline \multirow[t]{3}{*}{ Location } & Dublin city or county & 23 & $(87)$ \\
\hline & Another town or city & 29 & $(109)$ \\
\hline & A rural area & 47 & (176) \\
\hline
\end{tabular}

Range: 25 th to 75 th percentile, i.e. the middle $50 \%$ of values when all values are ordered from lowest to highest. 


\section{Place and cause of death, and health at end of life}

\section{Place and cause of death}

Place and cause of death are presented below in Figures 1 and 2. Nearly half (46\%) of deaths occurred in hospital, followed by the individual's own home $(27 \%)$, hospice $(11 \%)$ and nursing home (10\%) (Figure 1).

Figure 1. Place of death

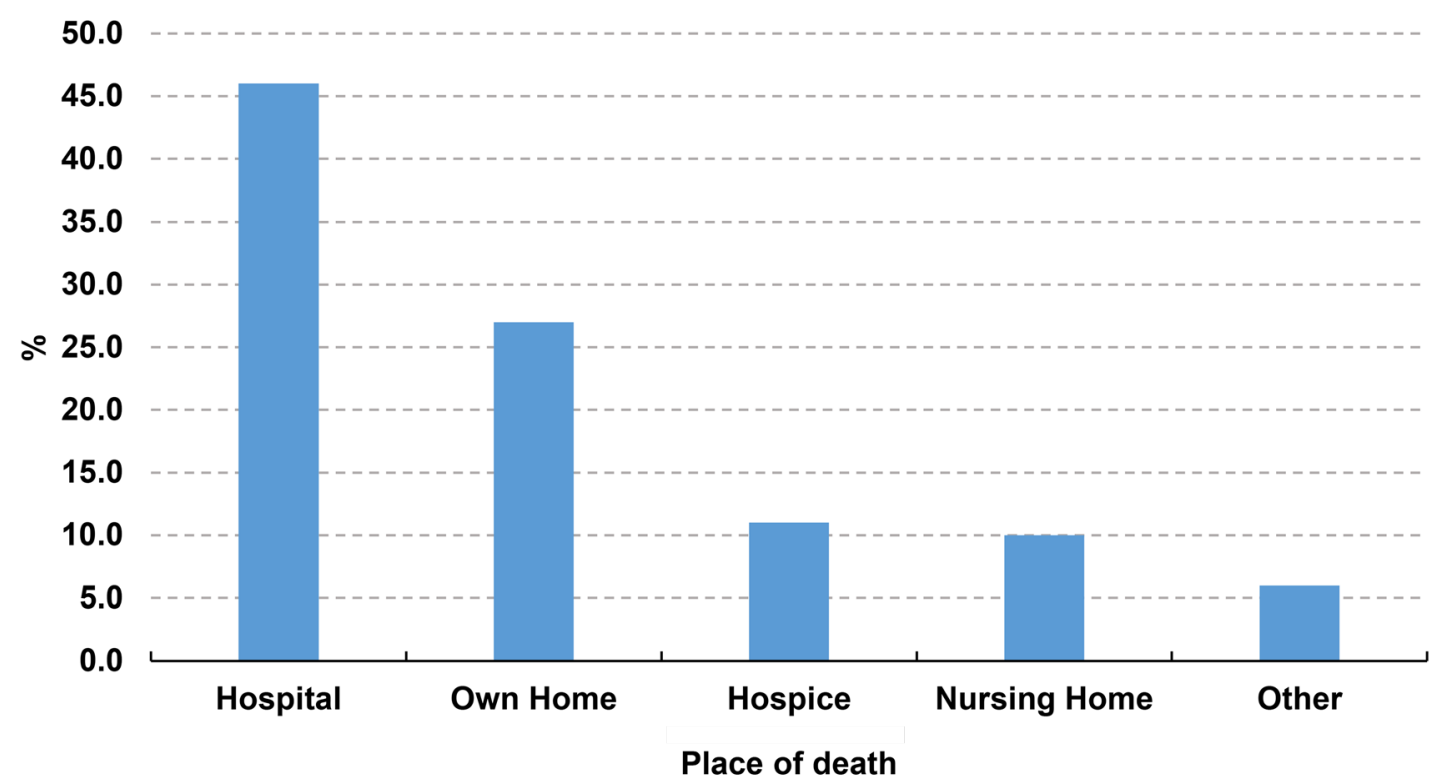


Figure 2 shows that the most common reported causes of death were cancer (38\%), and heart attack or other cardiovascular event (31\%). Other causes included respiratory failure, infection and gastrointestinal diseases.

These results differ from national statistics, which place cardiovascular disease as the leading cause of death and cancer second (Department of Health, 2017). The recruitment of participants from community-dwelling older adults means that the TILDA sample is on average younger and with a lower burden of long-term illnesses and more sudden deaths than Ireland's over-50 population overall. These differences will diminish over time because TILDA participants continue to be interviewed if they move into residential care.

Figure 2. Main cause of death

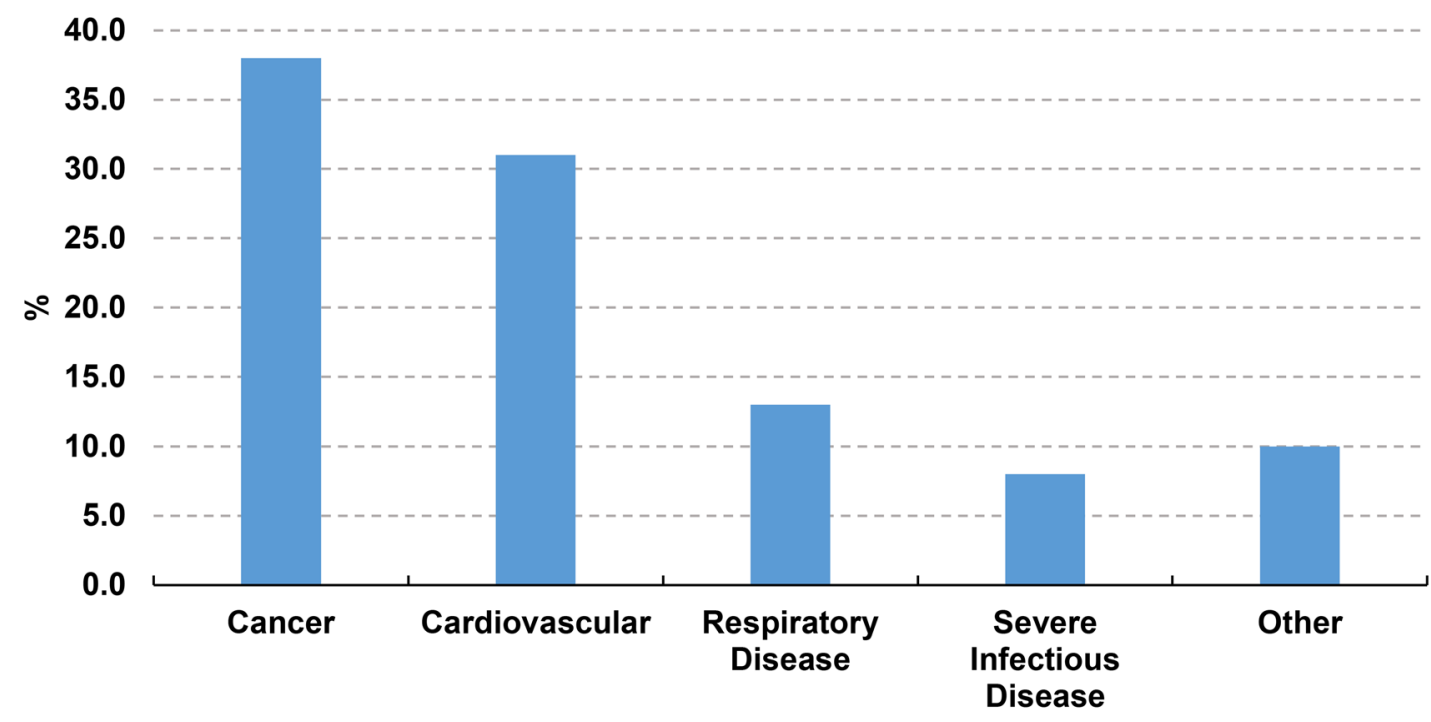

Main cause of death 


\section{Duration of ill-health and disability}

A summary of duration of ill-health and disability in the last year of life are provided in Figures 3-6. Duration of illness in the last year of life is detailed in Figure 3: $29 \%$ were ill for less than a month, of whom half died suddenly; $21 \%$ were ill for between one and six months; $17 \%$ were ill for between six and 12 months; and $33 \%$ were ill for more than a year.

Figure 3. Duration of illness prior to death

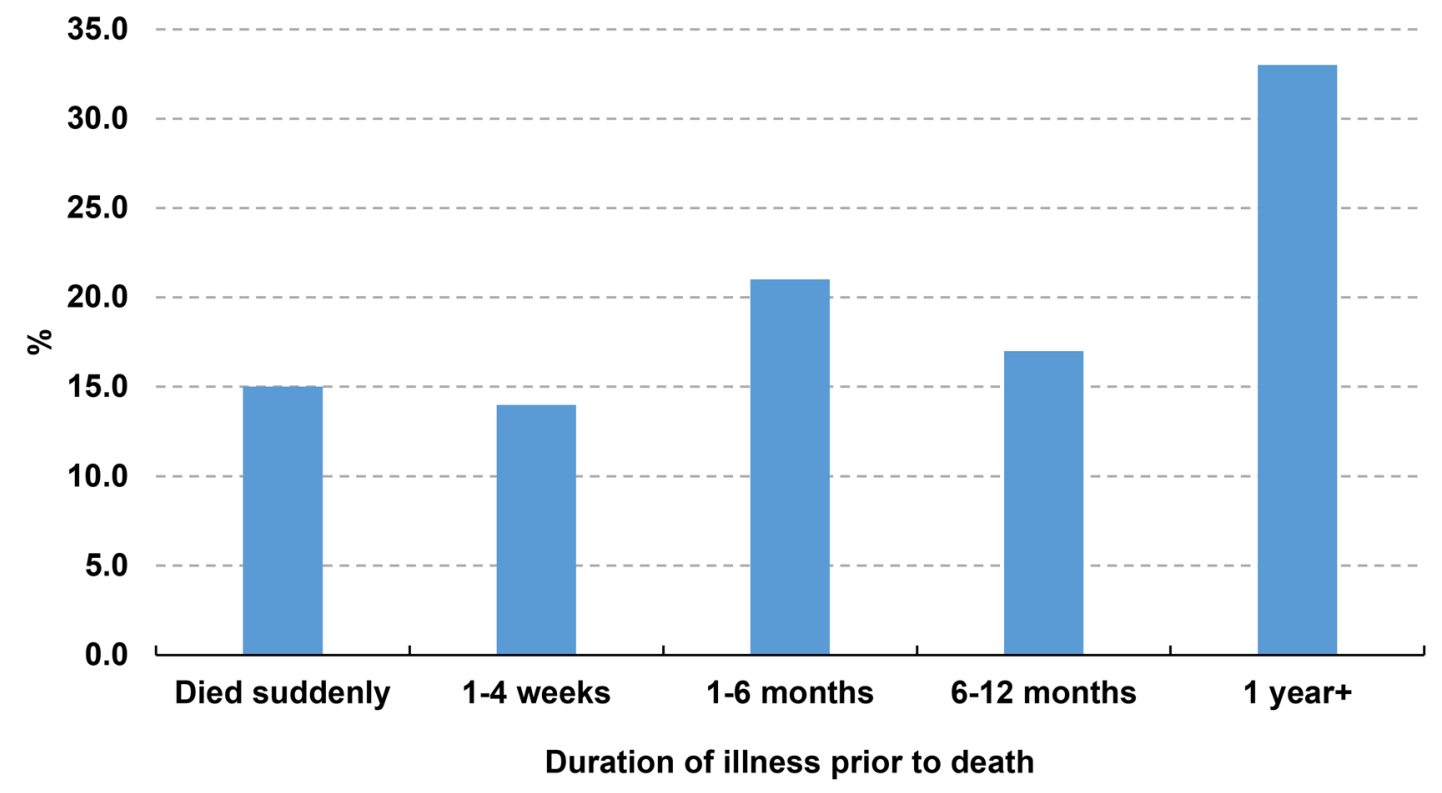


Disability in the last year of life was assessed in two ways. First, interview respondents were asked to describe the physical health of the deceased TILDA participant in the last year of life from the following options: (1) active and disability free; (2) mostly active and disability free, but declined during the last few months before [he/she] died; (3) had times of being seriously disabled, mixed with times of being active; (4) gradually become more and more disabled, without times of being active. The majority $(61 \%)$ of deceased participants are described as wholly or mostly disability-free in the last year of life, while $30 \%$ gradually became more disabled in the last year of life (Figure 4 ).

Figure 4. Description of health in last year of life

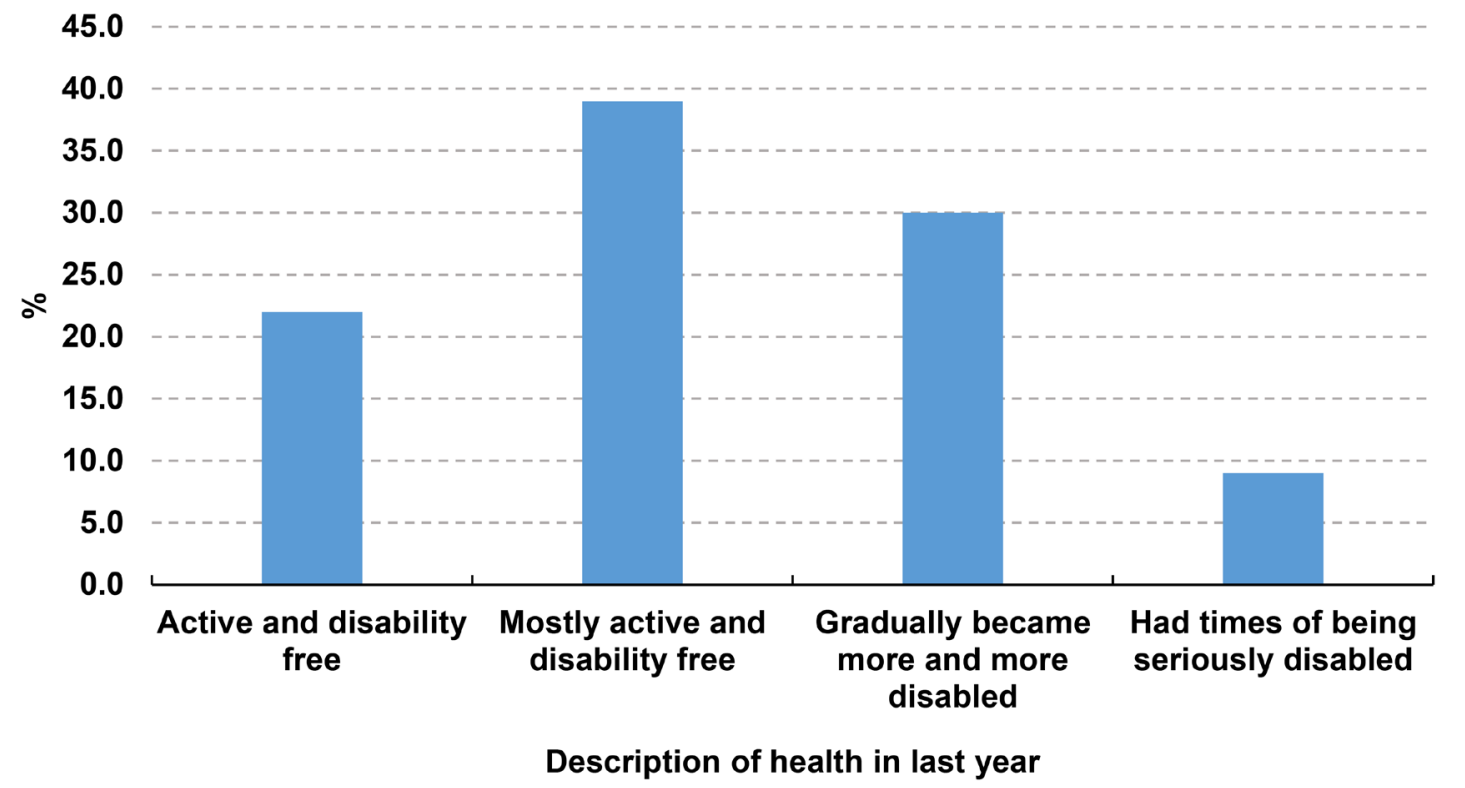

Second, respondents were asked about difficulties that deceased participants had with specific activities. Activities of daily living (ADL) measure difficulty with the following personal care tasks: dressing, crossing the room, bathing, getting in and out of bed, using the toilet and feeding (Katz et al., 1963). Instrumental activities of daily living (IADL) measure whether the person had difficulty with other activities key to living independently. These are: cleaning the home, preparing meals, shopping for necessities, making telephone calls, taking medications and managing finances (Lawton and Brody, 1969). Health professionals often use these activities as a measure of disability or functional status. In general, helping with IADLs requires home care assistance or lay help, whereas people with $A D L$ limitations require more professionally trained staff.

The proportion of TILDA respondents who had a difficulty performing each ADL and IADL in the last three months of life is shown in Table 2. Prevalence of specific difficulties ranged 
from $29 \%$ who had difficulty with making telephone calls to $56 \%$ who had difficulty with household chores. Figure 5 presents the total number of difficulties with the six measured ADLs and six measured IADLs. While $32 \%$ of deceased participants were described as having no difficulties, $33 \%$ had difficulty with at least nine of the 12 specified tasks in the last three months of life.

Table 2. Proportions of TILDA participants with difficulties performing Activities of Daily Living (ADL) and Instrumental Activities of Daily Living (IADL) in the last three months of life

\begin{tabular}{|c|c|c|c|c|}
\hline & & & $\%$ & (N) \\
\hline \multirow[t]{6}{*}{ ADL } & Difficulty with & Dressing & $43 \%$ & (160) \\
\hline & & Getting across a room & $38 \%$ & $(142)$ \\
\hline & & Bathing/showering & $49 \%$ & (183) \\
\hline & & Eating/preparing food & $35 \%$ & (132) \\
\hline & & Getting in/out bed & $40 \%$ & (151) \\
\hline & & Using toilet & $37 \%$ & (139) \\
\hline \multirow[t]{6}{*}{ IADL } & Difficulty with & Preparing hot meals & $52 \%$ & (196) \\
\hline & & Doing household chores & $56 \%$ & (209) \\
\hline & & Shopping for groceries & $55 \%$ & (205) \\
\hline & & Making telephone calls & $29 \%$ & (108) \\
\hline & & Taking medication & $36 \%$ & (134) \\
\hline & & Managing money \& bills & $35 \%$ & (133) \\
\hline
\end{tabular}


Figure 5. Proportion of participants who had difficulties performing a total number of ADL and IADL in the last three months of life

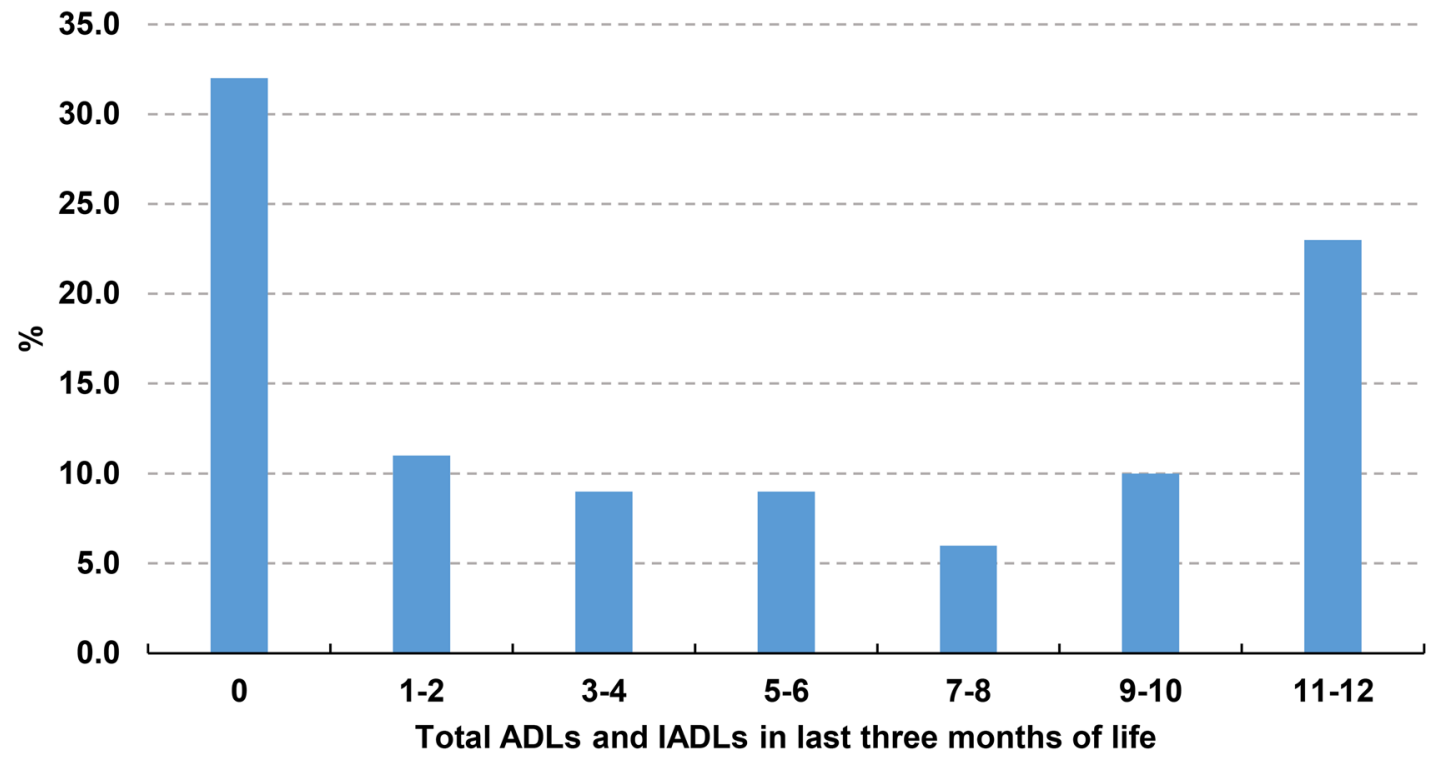

Note: Equivalent patterns are evident if the ADL and IADL data are presented separately.

Family members and friends of the deceased participant were also asked a number of questions about their physical health in their last year of life. We asked if the participant had experienced a fall in the last two years, and whether they experienced pain or depression in the last year of life. Significant proportions of deceased participants experienced falls $(41 \%)$, regular pain $(50 \%)$ and regular depression $(45 \%)$ towards the end of life. Importantly, these conditions are all modifiable. Raising awareness of the increased prevalence of these outcomes towards the end of life, can reduce their occurrence, through appropriate screening and diagnosis, treatment and medication, which would lead to an improvement in the quality of life of older people at end of life. 


\section{Health service use, and help from family and friends}

Family members and friends were asked a number of questions about health service use, and help received from family and friends in the last year of life. Importantly, they were also asked about services that the participant needed, but did not receive.

\section{Medical card holders and private health insurance}

A large majority of deceased participants (89\%) had either a full medical card or a GP visit card, while more than one third (38\%) also had private health insurance in the last year of life.

\section{GP and hospital visits, procedures, and other services use}

A summary of institutional visits and medical procedures is provided in Table 4. For all visits, mean usage is considerably larger than the median, indicating that a small number of participants accounted disproportionately for utilisation. On average participants visited the GP six times in the last year of life and experienced one hospital inpatient admission. A small proportion $(7 \%)$ had a heart procedure, while $27 \%$ had a cancer procedure, such as chemotherapy, medication, surgery, biopsy, radiation/x-ray and treatment for symptoms, in the last year of life. 
Table 3. Hospital and GP visits and medical procedures in last year of life

\begin{tabular}{|l|c|c|}
\hline & Mean & (Range) \\
\hline General Practitioner Visits & 10.2 & $(6)$ \\
\hline Emergency Department visits & 1.3 & $(0)$ \\
\hline Inpatient stays & 2.1 & $(1)$ \\
\hline Outpatient visits & 5.0 & $(1)$ \\
\hline Day case procedures & 1.6 & $(0)$ \\
\hline Operation with anaesthetic & 0.4 & $(0)$ \\
\hline Heart procedure & $\%$ & $(\mathrm{~N})$ \\
\hline Cancer procedures & $7 \%$ & $(28)$ \\
\hline
\end{tabular}

Heart procedures: Cardiac catheterization, coronary angiogram, angioplasty, bypass graft notation, surgery. Cancer procedures: chemotherapy, medication, surgery, biopsy, radiation/x-ray, treatment for symptoms.

\section{Residential care, home care and other services}

Table 4 shows the number of residential care stays in the last two years of life.

A minority of older adults used residential care services in the last two years, including those who moved into those settings as a main dwelling. Twelve percent stayed in a hospice, with a median stay of four days; $18 \%$ stayed in a nursing home, with a median stay of 60 days; and $8 \%$ stayed in the home of a family member or friend, with a median stay of 19 days.

Table 4. Residential care in the last two years of life

\begin{tabular}{l|cc|cc} 
& \multicolumn{2}{c|}{ Spent time } & \multicolumn{2}{c}{ Total nights } \\
& Yes & $\%$ & Mean & Median \\
\hline Hospice & 44 & $12 \%$ & 16 & 4 \\
\hline Nursing home & 67 & $18 \%$ & 164 & 60 \\
\hline Another's home & 29 & $8 \%$ & 93 & 19 \\
\hline Total nights data for those participants who spent any time in the setting.
\end{tabular}


Table 5 shows the proportion who received publicly provided home care services while the other publicly provided community care and allied health services are shown in Table 6. Home care services received in the last year of life were as follows; $19 \%$ received home help, $9 \%$ had a personal care attendant and $6 \%$ received meals on wheels. Almost half received community care services (45\%) (e.g. public health nurse, day centre) and $33 \%$ used allied health services (e.g. physiotherapy, dental, hearing). Again, in all cases the mean is larger than the median indicating a relatively small number of high-users.

Table 5. Home care services received in last year of life
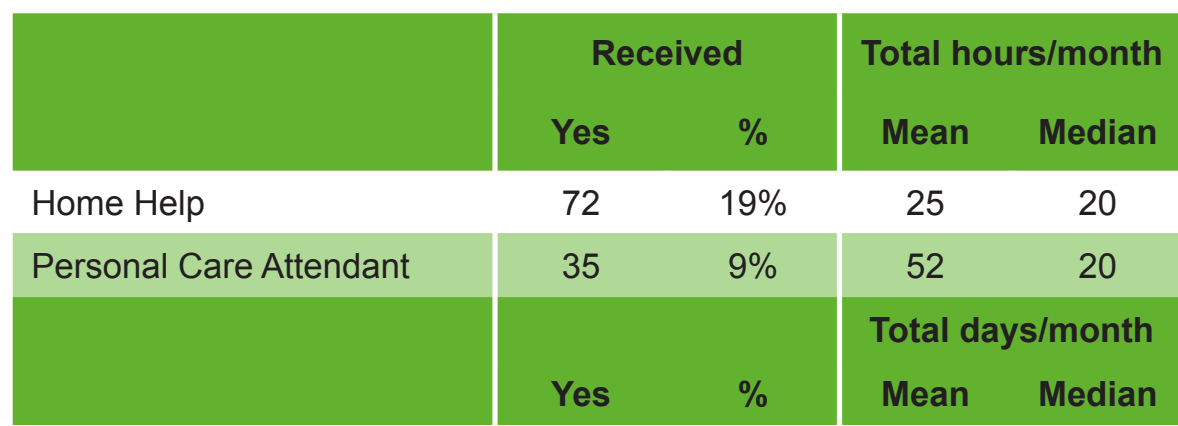

Meals on Wheels

\begin{tabular}{|c|c|}
\hline 72 & $19 \%$ \\
\hline 35 & $9 \%$ \\
\hline & $\%$ \\
\hline
\end{tabular}

21

25

52

$6 \%$

20

20

Total days/month

Mean Median

$12 \quad 8$

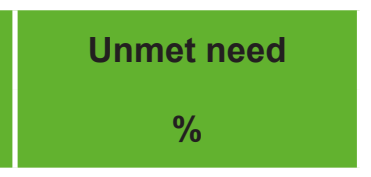

$16 \%$ $20 \%$

$20 \%$

$25 \%$

Total use data for those participants who accessed service.

'Unmet need' calculated as the number of people seeking but unable to access the service as a proportion of all people seeking the service.

Table 6. Other services used and unavailable in last year of life

\begin{tabular}{|c|c|c|c|}
\hline & $\begin{array}{l}\text { Used at lea } \\
\text { Frequency }\end{array}$ & $\begin{array}{l}\text { service } \\
\%\end{array}$ & $\begin{array}{c}\text { Unmet need } \\
\%\end{array}$ \\
\hline Community Care ${ }^{1}$ & 167 & $45 \%$ & $15 \%$ \\
\hline Allied Health Care ${ }^{2}$ & 123 & $33 \%$ & $30 \%$ \\
\hline
\end{tabular}

${ }^{1}$ Community Care: Public Health Nurse, day centre, respite care.

${ }^{2}$ Allied Health Care: Occupational therapy, chiropody services, physiotherapy, speech \& language therapy, social worker, psychological/counselling services, optician, dentist, hearing service, dietician.

'Unmet need' calculated as the number of people unable to access at least one service as a \% of all people seeking services. 
A summary of the proportion of deceased participants who sought but could not access services in the last year of life is also provided in Table 5 and Table 6. In each case, substantial proportions of older people (15-30\%), whose family members and friends reported that they needed the services, were unable to access home care, personal care attendants, meals on wheels, community care and allied health services. The reported reasons for lack of access to services are presented in Figure 7. Twenty-seven per cent of such instances are accounted for by people being reluctant to apply for care services while another $18 \%$ did not know these services were available and a further $16 \%$ were not eligible for the services.

Figure 7. Reasons for lack of access to home care, community care and allied health services

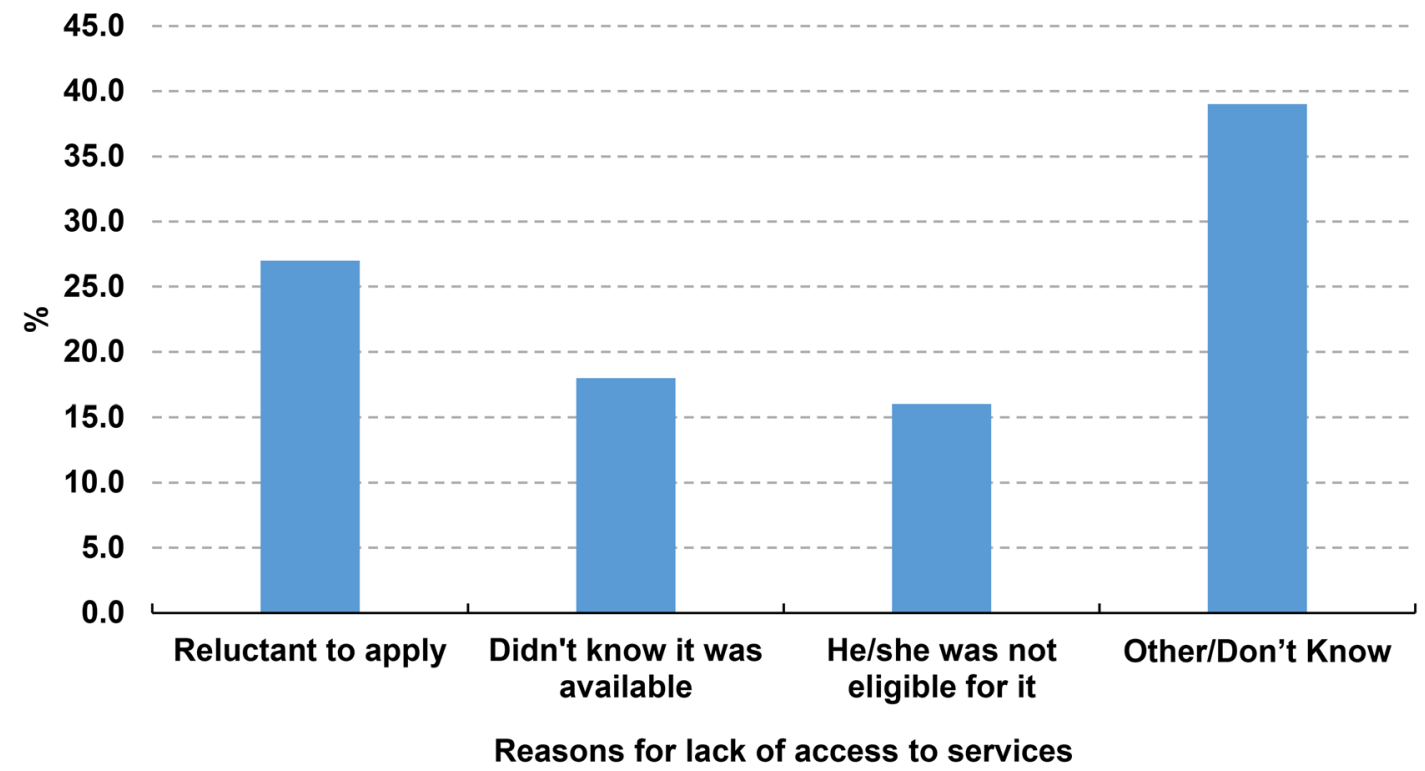

\section{Helpers and informal care}

In Chapter 3, Figure 5 shows that in the last three months of life people needed help with a variety of everyday activities, such as getting into and out of bed, washing and preparing meals. On average people needed assistance with 3-4 activities, with $33 \%$ of people needing help with at least nine of the 12 specified tasks.

Where participants lived in a nursing home or received regular home care services, at least some of this help was typically provided by healthcare professionals. However, as is shown in Table 5 and Table 6 , a minority of the deceased TILDA participants used such services in the last year of life. Consequently, a large majority of help with (instrumental) activities of daily living was provided to older adults at end of life by family-and-friend 
networks, also known as 'informal care'. A summary of help from family and friends in performing everyday tasks in the last three months of life is shown in Table 7.

On average, deceased participants received help from one person providing two hours of assistance per day in the last three months of life. The higher mean number of helpers and hours per day indicates a small number of people receiving much higher levels of care: $40 \%$ of people received no help at all while $10 \%$ received 24 -hour care from family and friends at end of life.

In some circumstances, family-and-friend helpers can access financial supports such as the HSE Carer Allowance, and in some cases older people and their families paid helpers from their own resources. However, over three quarters of deceased participants $(76 \%)$ helped by family and friends received fully unpaid assistance in the last three months of life.

Table 7. Care from family-and-friend helpers in last three months of life

\begin{tabular}{l|c|c|} 
& Mean & Median \\
\hline Number of family-and-friend helpers & 1.3 & 1 \\
\hline Total hours of family-and-friend help per day & 6 & 2 \\
\hline People who received some help from family and friends & $\mathbf{N}$ & $\%$ \\
\hline People who received 24-hour help from family and friends & 226 & $60 \%$ \\
\hline People receiving family-and-friend help that was fully unpaid & 172 & $10 \%$ \\
\hline
\end{tabular}

\section{Estimated cost of healthcare in last year of life}

The cost of care to deceased participants in their last year of life is estimated in Table 8. The costs of formal healthcare were calculated based on services used and paid hours of care received. In addition, the costs of informal care hours were estimated to measure and illustrate the amount of unpaid care provided by family and friends, and to inform efforts to balance the burden on informal care networks with care from the formal care system. The average total cost of care in last year of life was $€ 47,479$. Formal care accounted for $€ 27,730$ (58\%) and informal care from family and friends accounted for $€ 19,748$ (42\%). Over $50 \%$ of formal care costs were comprised of hospital care costs. Both formal and informal care costs had higher mean than median, indicating that a minority of deceased participants accounted disproportionately for care received: $5 \%$ of people accounted for approximately $15 \%$ of total care costs. 
Table 8. Estimated cost of care (formal and informal) in last year of life (€)

\begin{tabular}{|c|c|c|}
\hline & Mean & Median \\
\hline Primary/community care ${ }^{1}$ & 3252 & 2639 \\
\hline Hospital care ${ }^{2}$ & 15319 & 8291 \\
\hline Residential care $^{3}$ & 4264 & 0 \\
\hline Home care ${ }^{4}$ & 4896 & 0 \\
\hline Total (Formal care) & 27730 & 19967 \\
\hline Informal care ${ }^{5}$ & 19748 & 6192 \\
\hline Total Cost of care ${ }^{6}$ & 47479 & 37175 \\
\hline
\end{tabular}

${ }^{1}$ Primary/community care: GP, pharmacy; all community and allied health care in Table 6.

${ }^{2}$ Hospital: ED, inpatient, outpatient.

${ }^{3}$ Residential: Hospice, nursing home.

${ }^{4}$ Home care: all services in Table 5 plus paid-for home modifications and paid-for home carers, and HSE carer allowance.

IInformal care: unpaid care in the last three months of life in Table 7, combined with nine months of participant-reported informal care in their last TILDA interview prior to death.

${ }^{6}$ Total cost of care: Formal plus informal care; mean total costs is therefore the sum of formal and informal means.

Given the wide variety in health and illness burden observable in Chapter 3, and the evidence of a minority of high-intensity users in Table 8, it is important to examine how service utilisation varies between people whose health at end of life was good and those who lived with severe or growing illness and disability burden. 
The costs of care are presented in Table 9, stratified by the participating person's health in last year of life (Figure 4; people described as mostly or wholly active and disability free were grouped together as in 'good health'). Formal costs are approximately 50\% lower among people in good health and informal care costs are approximately $66 \%$ lower. Differences in formal care are driven by lower hospital, residential and homecare use by those in good health.

These are very large differences that emphasise the importance of differences in need and circumstance that must be considered in preparing policy and healthcare responses to older adults at end of life.

Table 9. Estimated cost of care (formal and informal) in last year of life (€)

\begin{tabular}{|l|c|c|cc}
\multicolumn{1}{c|}{ Good health in last year of life } & \multicolumn{2}{c|}{ Yes $(\mathbf{n = 2 2 6 )}$} & \multicolumn{2}{c}{ No $(\mathbf{n = 1 4 9 )}$} \\
& & & & \\
& Mean & Median & Mean & Median \\
\hline Primary/community care & 3004 & 2510 & 3628 & 2890 \\
\hline Hospital care & 13042 & 7894 & 18772 & 13874 \\
\hline Residential care & 1653 & 0 & 8226 & 0 \\
\hline Home care & 2815 & 0 & 8053 & 2000 \\
\hline Total (Formal care) & 20514 & 14576 & 38678 & 29671 \\
\hline Informal care & 11225 & 1258 & 32675 & 17415 \\
\hline Total Cost of care & 31739 & 23280 & 71353 & 61575 \\
\hline
\end{tabular}




\section{Key associations with end- of-life experience}

Chapters 3 and 4 have described the end-of-life experience of a group of older adults in Ireland as well as summarising the formal healthcare and unpaid help that these adults received at end of life.

This chapter presents the most important associations between participant characteristics and service use that have important implications for end-of-life experience, using multivariate regression techniques. Interpreting these associations can help to understand how patterns of experience are related to care needs, as well as to sociodemographic and healthcare system factors. This understanding can inform provision of effective care, to identify underserved populations and unmet need, and to reduce inappropriate care.

\section{What outcomes were examined?}

We identified three service-use outcomes in the TILDA end-of-life interview responses that have important implications for end-of-life experience: place of death, unmet need and cost of care received. These outcomes are summarised in Table 10.

Table 10. Description of outcomes with important implications for end-of-life experience

\begin{tabular}{l|l}
\hline Outcome & Description \\
\hline Place of death (Figure 1) & Where the person died. \\
\hline Unmet need (Table 6, Table 7) & $\begin{array}{l}\text { If the person who died needed, but was unable } \\
\text { to access, home care, community care or allied } \\
\text { health care services in the last year of life. }\end{array}$ \\
\hline Cost of care received (Table 9) & $\begin{array}{l}\text { The estimated cost of formal healthcare, and of } \\
\text { unpaid care from family and friends, provided } \\
\text { to the person who died in the last year of life. }\end{array}$ \\
\hline
\end{tabular}




\section{What associations were analysed?}

To identify variables that may be associated with the outcomes in Table 11, we employed Anderson's conceptual model of healthcare to compile indices of predisposing, enabling and need characteristics (Andersen, 1995):

Predisposing characteristics are individual propensities to use services which exist prior to the onset of illness. These may include; age, sex and domestic situation.

Enabling characteristics are the means individuals have at their disposal to avail of services. These include both resources specific to the individual and his/her family (e.g. income, entitlement status) and attributes of the community in which the individual lives (e.g. rural/urban).

Need characteristics reflect the need for healthcare and so typically relate to the severity of illness or incapacity.

\section{Table 11. Description of characteristics potentially associated with end-of-life experience}

\begin{tabular}{|c|c|}
\hline Characteristic & Description \\
\hline \multicolumn{2}{|l|}{ Predisposing } \\
\hline Age & How old the person who died was at the time of their death \\
\hline Sex & Sex of the person who died \\
\hline Living situation & If s/he lived alone, with a partner or spouse, or with other family and friends \\
\hline \multicolumn{2}{|l|}{ Enabling } \\
\hline Education & Highest level of education achieved \\
\hline Location & Area of Ireland lived in \\
\hline Medical card & Medical card/GP visit card status \\
\hline Health insurance & If s/he had private health insurance \\
\hline \multicolumn{2}{|l|}{ Need } \\
\hline Heart disease & $\begin{array}{l}\text { If s/he ever had one or more of the following indicators of heart disease: a heart attack, } \\
\text { angina, congestive heart failure, stroke. }\end{array}$ \\
\hline Cancer & If s/he had ever been diagnosed with cancer. \\
\hline Multimorbidity & $\begin{array}{l}\text { If at the time of their death s/he had two or more serious chronic conditions (e.g. heart } \\
\text { disease; cancer; dementia; liver, kidney or respiratory failure) }\end{array}$ \\
\hline Physical Health & S/he was wholly or mostly active and disability free in the last year of life \\
\hline Mental Health & S/he was sometimes or frequently depressed in the last year of life \\
\hline ADL (Total) & $\begin{array}{l}\text { Total of six activities with which s/he required help in the last three months of life: } \\
\text { dressing, crossing a room, bathing, eating, getting in/out of bed, using the toilet }\end{array}$ \\
\hline IADL (Total) & $\begin{array}{l}\text { Total of six activities with which s/he required help in the last three months of life: } \\
\text { preparing hot meals, household chores, shopping for groceries, making telephone calls, } \\
\text { taking medication, managing money \& bills }\end{array}$ \\
\hline Short illness & S/he was ill for less than a week before they died \\
\hline
\end{tabular}

Sources: Sex, Living situation, Education and Location were taken from the Participant responses in the last Wave of TILDA before $\mathrm{s} /$ he died. Presence of serious chronic conditions (heart disease, cancer and multimorbidity) were identified by combining all Waves in which the Participant took part as well as the end-of-life interview responses. All other characteristics were drawn from the end-of-life interview only. 


\section{Statistical methods}

To determine the association between these predisposing, enabling and need characteristics and place of death, unmet need and cost of care received, we performed a multivariate regression with a fixed list of explanatory variables (all variables in Table 11) for each dependent variable in Table 10. For place of death and unmet need, we used logistic regression and estimated associations using odds ratios (OR). The OR is a measure of association between a variable and an outcome: if $\mathrm{OR}=1$ then variable is not associated with outcome; if $\mathrm{OR}>1$ then variable is associated with higher odds of outcome; if $\mathrm{OR}<1$ then variable is associated with lower odds of outcome. For costs we used a generalised linear model with a gamma distribution and a log link and estimated the marginal association ( $d y / d x)$ for each variable. For binary variables $d y / d x$ reflects the estimated effect of moving from the reference case to the specified case; for continuous variables the $d y / d x$ reflects the estimated effect of increasing the variable by a unit of 1 . For example, the $\mathrm{dy} / \mathrm{dx}$ for 'did the person have private health insurance?' is the estimated impact on costs in euros of a person having private health insurance compared to not having it, holding all other values constant; the $d y / d x$ for age is the estimated impact on costs in euros of increasing a person's age by one year, holding all other values constant.

\section{Place of death}

There are four principal places of death for the participants: home (27\%), hospital (46\%), hospice (11\%) and nursing home (10\%) (Figure 1). The estimated associations of the characteristics of the deceased older adults with place of death are presented in Table 12. Statistically significant associations $(p<0.05)$ are highlighted in bold. People who lived alone were half as likely to die at home as those who lived with others, and 3.8 times more likely to die in a nursing home. People living in rural areas were less likely to die in a nursing home than those living in non-Dublin urban areas. People with cancer were more likely to die in a hospice and less likely to die in a nursing home. As age increased, people were more likely to die in a nursing home. Increasing difficulties with ADLs was also associated with place of death being in a nursing home. 

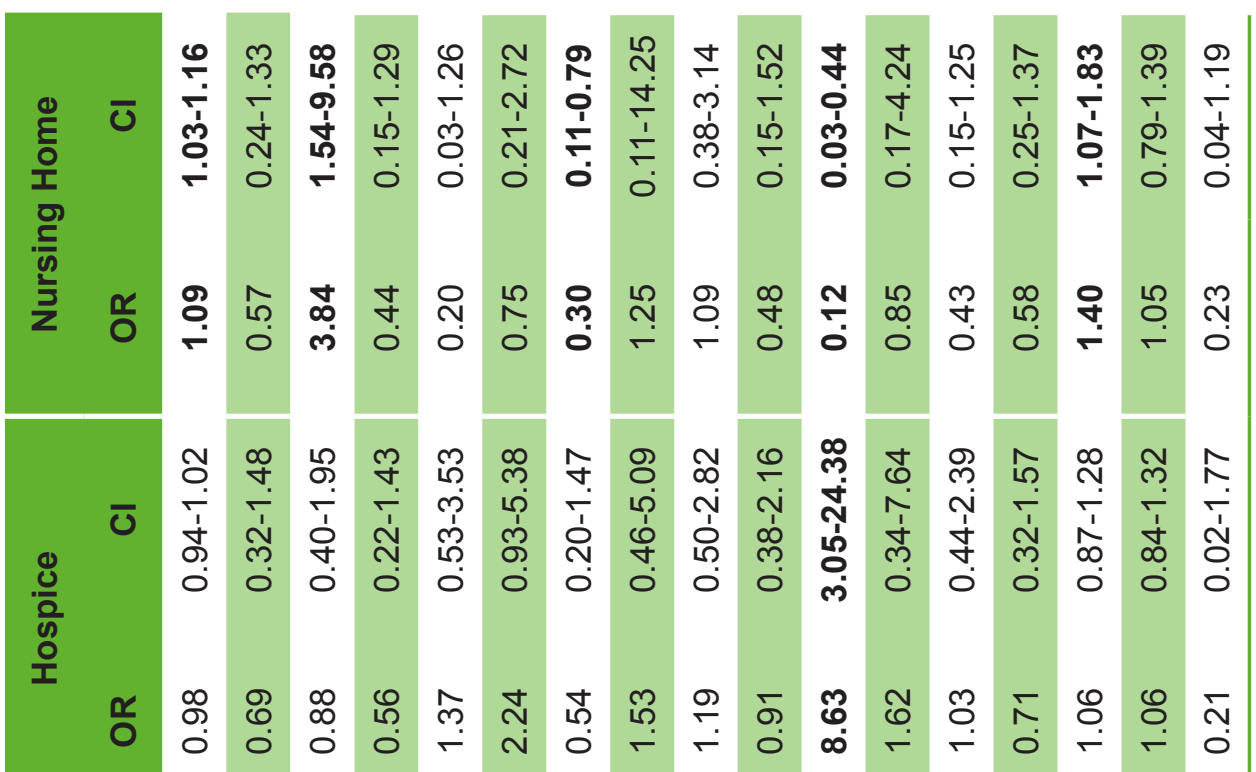

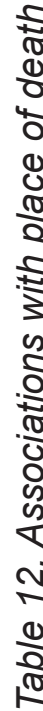
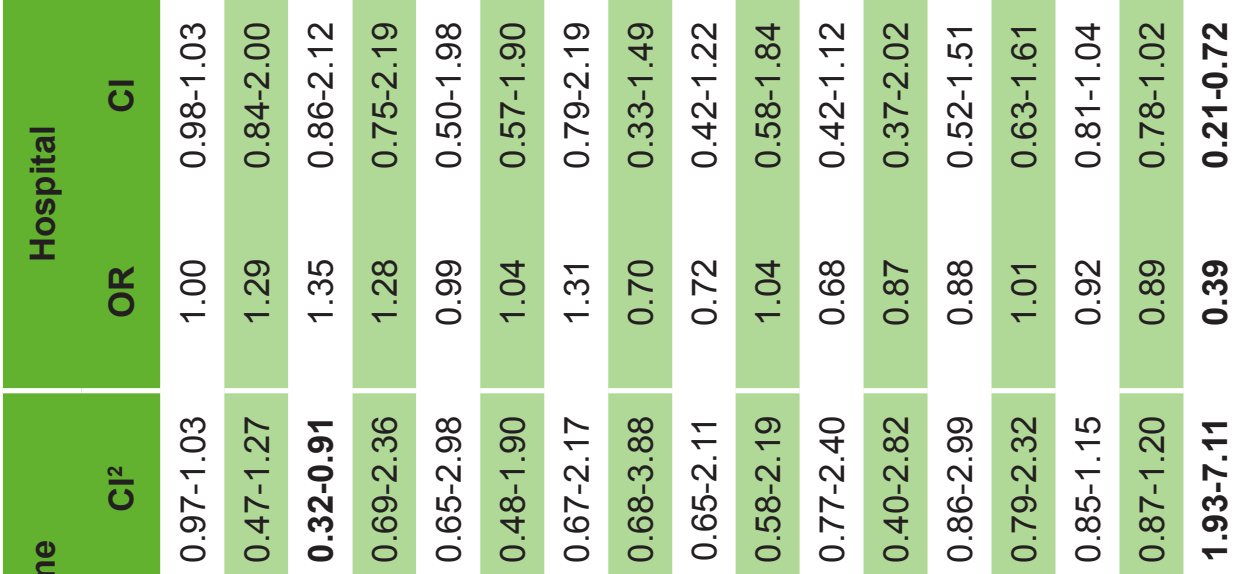

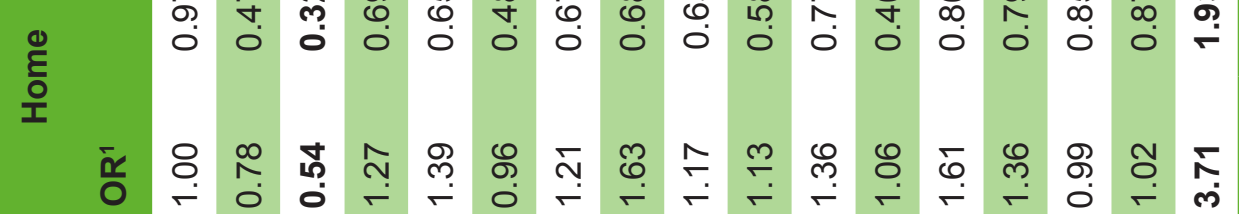

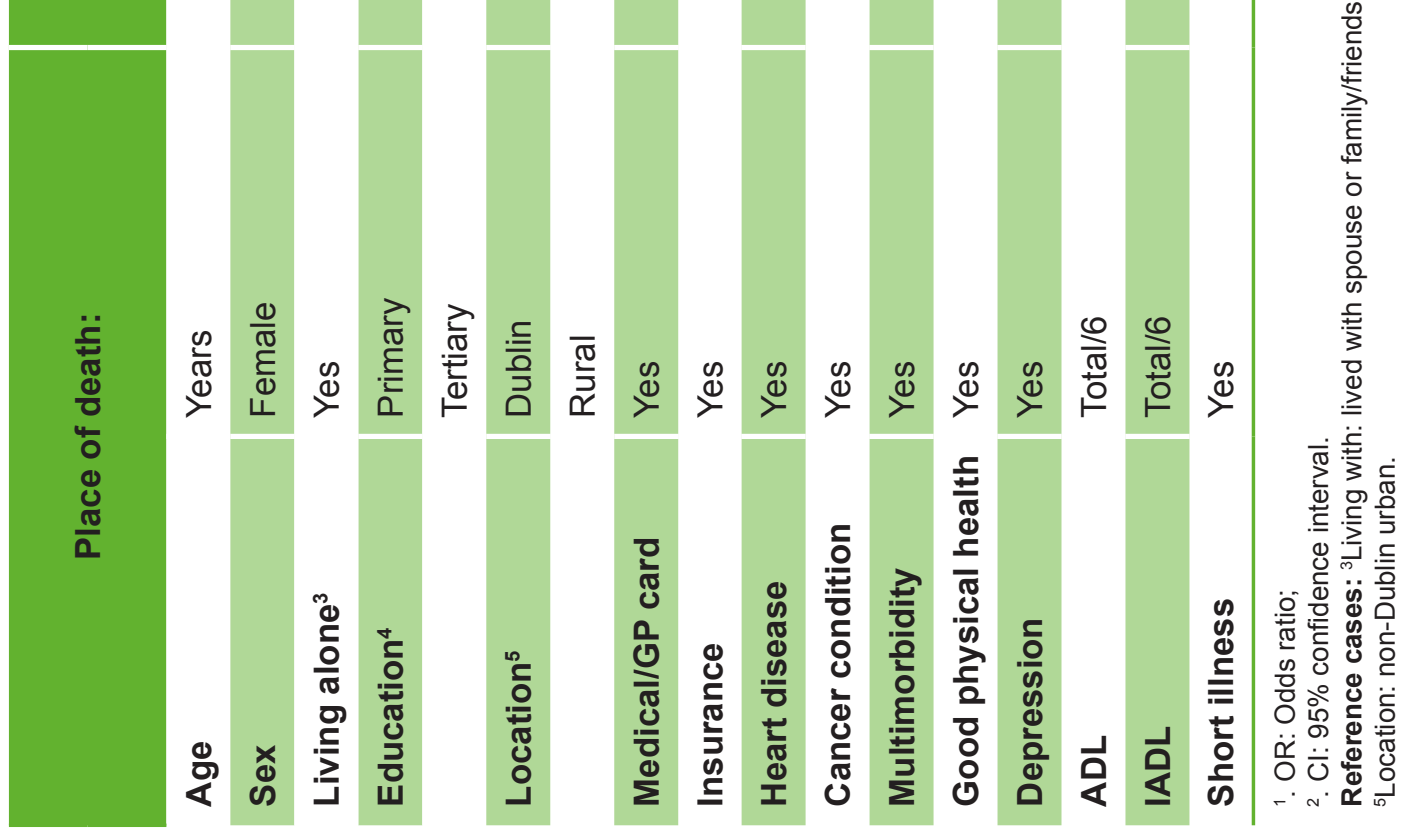




\section{Unmet need}

Between $15 \%$ and $30 \%$ of people who needed state services including home care, community care and allied health care, in the last year of life were unable to access the service (Table 5, Table 6). The characteristics that were associated with unmet need are presented in Table 13. There are two statistically significant associations $(p<0.05)$ which are highlighted in bold. Both heart disease and depression were independently associated with unmet need. People with a history of heart disease were nearly three times as likely to try unsuccessfully to access a service than those without, and those with depression were over twice as likely to fail to access a service than people without depression. No other characteristic is found to be associated with lack of access to state services.

\section{Table 13. Associations with place of death}

\begin{tabular}{|c|c|c|c|}
\hline \multicolumn{2}{|c|}{$\begin{array}{l}\text { Did s/he try unsuccessfully to access a } \\
\text { service? }\end{array}$} & \multicolumn{2}{|c|}{ Yes } \\
\hline Age & Years & 0.99 & $0.96-1.02$ \\
\hline Sex & Female & 1.46 & $0.85-2.50$ \\
\hline Living alone ${ }^{3}$ & Yes & 1.42 & $0.81-2.48$ \\
\hline \multirow[t]{2}{*}{ Education ${ }^{4}$} & Primary & 1.26 & $0.63-2.53$ \\
\hline & Tertiary & 1.98 & $0.84-4.68$ \\
\hline \multirow[t]{2}{*}{ Location $^{5}$} & Dublin & 1.21 & $0.59-2.50$ \\
\hline & Rural & 0.98 & $0.52-1.87$ \\
\hline Medical/GP card & Yes & 1.39 & $0.49-3.96$ \\
\hline Insurance & Yes & 0.78 & $0.40-1.52$ \\
\hline Heart disease & Yes & 2.94 & $1.26-6.83$ \\
\hline Cancer condition & Yes & 1.15 & $0.63-2.10$ \\
\hline Multimorbidity & Yes & 0.94 & $0.25-3.47$ \\
\hline Good physical health & Yes & 0.86 & $0.45-1.63$ \\
\hline Depression & Yes & 2.32 & $1.29-4.17$ \\
\hline ADL & Total/6 & 0.92 & $0.79-1.08$ \\
\hline IADL & Total/6 & 1.08 & $0.91-1.29$ \\
\hline Short illness & Yes & 1.15 & $0.53-2.49$ \\
\hline
\end{tabular}


Healthcare costs in last year of life

Average total cost of care in last year of life was estimated to be $€ 47,479$, accounted for $€ 27,730$ (58\%) by formal healthcare services and $€ 19,748$ (42\%) by unpaid informal care from family and friends (Table 8). The estimated marginal association (dy/dx) of each characteristic with formal, informal and total costs is presented in Table 14.

Table 14 shows that increasing age is associated with higher informal care costs, but not formal care costs. Living alone is associated with lower informal care costs, relative to those who were married or lived with family, and with an overall reduction in total care costs. Good physical health, defined as mostly active and disability free, was associated with lower formal healthcare costs and overall total costs compared to those who were not. ADLs were associated with increased formal and informal care costs, and IADLs were associated with increasing informal care costs. 


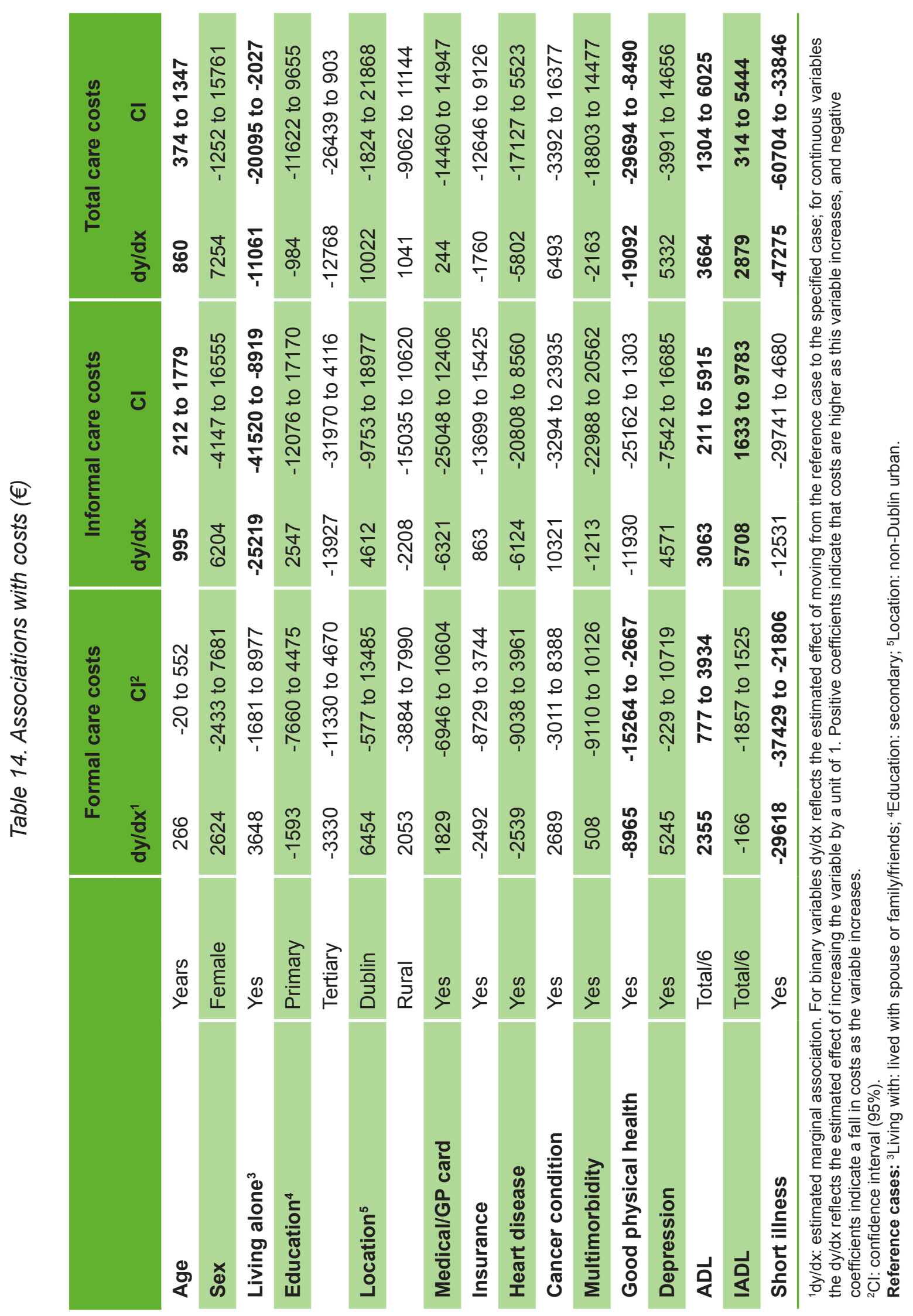




\section{Discussion}

Key results

The first TILDA report on end-of-life experience for older adults in Ireland demonstrates a wide variation in health and illness burden. Of the 375 TILDA participants for whom a family member or friend completed an end-of-life interview, approximately a third were disability-free while another third needed help with at least nine of 12 everyday tasks such as eating, bathing and taking medications. Similarly, $29 \%$ were described as suffering illness for less than a month prior to death, of whom half died suddenly, and $33 \%$ were ill more than a year.

In addition to a high prevalence of non-modifiable conditions such as serious chronic illness, significant proportions of older people experience modifiable health problems towards the end of life, including falls $(41 \%)$, regular pain $(50 \%)$ and regular depression (45\%). Recognising the risk and presence of such modifiable conditions by practitioners is essential to improving end-of-life experience, since appropriately addressing these challenges is associated with better quality of life (Callis, 2016, Morrison et al., 2006, Goldman et al., 1999).

Reported healthcare usage by older adults increases in the last year of life but there is no clear evidence of the highly intensive end-of-life care that is seen, for example, in the United States and is associated with inappropriate care and undesirable outcomes (Meier, 2011). On average, TILDA participants visit the GP six times in the last year of life as well as experiencing one hospital inpatient admission. GP visits, and inpatient, outpatient and ED hospital admissions are higher among those at end of life than for all older adults in the TILDA study (Nolan et al., 2016). A minority of TILDA participants who died, spent time in hospice $(12 \%)$ and nursing home facilities (18\%). Higher proportions used home care services such as home help (20\%), community care such as public health nurse $(45 \%)$, and allied health care such as physiotherapy (33\%) in the last year of life.

\section{A high proportion of people who needed home, community and allied health} services were unable to access them. However, this unmet need is not found to be associated with other factors such as disability, socioeconomic status or location in Ireland. 
It is perhaps surprising that socioeconomic and geographic factors are not presenting particular barriers but reasons for failure to access services suggests that substantial numbers of people are unaware of services and/or reluctant to apply, which should be of immediate relevance and interest to policy-makers.

On average unpaid friend-and-family networks provided two hours of help per day at end of life but $10 \%$ of people received 24 -hour unpaid care. When the cost of this care is estimated alongside formal care costs in the last year of life, unpaid help from friendand-family networks accounts for $\mathbf{4 2} \%$ of the total cost of care received. These cost estimates are consistent with one previous study of an end-of-life population in Ireland (Brick et al., 2015). International comparisons are complicated by differences in societies and systems, as well as a lack of high-quality population-level data in other countries (Georghiou and Bardsley, 2014).

Averages for the overall group must be interpreted carefully as these cover important differences in care associated with illness burden. A minority of high-intensity users accounted for a majority of care from both the formal system and informal helpers. People described as being mostly or wholly active and disability-free in the last year of life used half the formal healthcare services and a third of the unpaid informal help compared to those otherwise described. This variety of illness burden implies substantial differences in need and circumstance that must be considered in preparing policy and healthcare provision for older adults at end of life.

As expected, physical health is an important driver of both healthcare services and unpaid help among older people in the last year of life. However, other determinants of service use and other experience are also observable.

First, there were important differences according to domestic situation. People who lived alone were less likely to die at home and more likely to die in a nursing home. They received less informal care from unpaid networks, but this was not offset by increased service usage. People living alone therefore appear to have received less overall care than those who live with others. These results emphasise the importance of domestic situation for end-of-life experience and the need for additional supports from the formal healthcare system for people who live alone to substitute for the informal care that is less available to them.

Second, people living in rural areas were less likely to die in a nursing home than those in urban areas. While a majority of people prefer not to die in an institutional setting if 
possible, these results may be indicative of a lack of supply of residential care in some parts of the state.

Third, unmet need is higher among those with a history of heart disease and those with depression but neither heart disease nor depression is associated with higher use of formal or informal care.

Fourth, and consistent with previous analysis of TILDA data (McNamara et al., 2013), age is not found to be an independent driver of formal healthcare use among older people. Rather, factors associated with age such as poor physical health are the key factors have a greater influence on formal healthcare use. However, age is an important factor in informal care in the last year of life - older people received significantly more hours of unpaid care from family and friends.

The finding that nearly half of deaths occurred in hospital is consistent with a previous study in Ireland (McKeown et al., 2010). Research from seven other high-income countries report the death-in-hospital rate between 22\% and 52\% (Bekelman et al., 2016), placing Ireland at the higher end of this group. A high hospital death rate is generally considered an indicator of poor health system performance since it is inconsistent with patient preferences (Gomes et al., 2012) and associated with both high resource use and poor patient experience (Teno et al., 2013).

Strategies that reduce unintended and unnecessary acute hospital admissions for people near end of life, as well as approaches that expedite discharge from hospital to a more appropriate setting, could potentially improve patient and family experience of the end-oflife phase while saving money for the healthcare system. Any such strategies, however, have to also be responsive to the fact that hospital is the preferred and appropriate place of death for some, when complex needs cannot be appropriately met at home with strong reliance on informal networks (Bakitas and Dionne-Odom, 2017). There is no evidence that hospital death is associated with any specific socioeconomic or clinical factors.

\section{Limitations}

The process of selecting the TILDA sample ensured that it closely matches the population over 50 in Ireland in terms of socioeconomic conditions, geography and age (Kenny et al., 2010). However, the fact that only community-dwelling older people were recruited at the start of the study means that it will take some time for the TILDA population at the end of life to fully match the wider population of older people near the end of life. Since the 
study follows people who are admitted to residential care these differences are diminishing over time, but care needs to be taken in interpreting the patterns found in the early endof-life interviews. As expected in this context the average age of the TILDA deaths is a little younger than the population overall. The results we report in Figure 2 reflect a higher number of cancer deaths and lower number of circulatory- and respiratory-disease deaths compared to population-level data. These differences should be considered in drawing conclusions about the experience of approaching the end of life in Ireland, and adjustments made in any projections of levels of need and unmet needs in Ireland.

Second, while the $73 \%$ response rate from family members and friends is high, there are potentially differences between the data reported here and the $27 \%$ of participants for whom no end-of-life interview was completed. For example, this latter group may have been more ill and more likely on average to live alone. Third, it is likely that some participants who have dropped out of the study but are not confirmed as died have died, and this group may also differ systematically from the sample that we present. Fourth, use of interviews from family members and friends may misrepresent results if there is a mismatch between the TILDA participant experience and the interviewees understanding/ memory of symptoms, illness experience and service use (George, 2002). For example, it is possible that the high proportion of cancer deaths is attributable not only to the TILDA sampling strategy but also to respondents' knowledge of cause of death.

Estimates of cost rely on assumptions in deriving unit cost data as well as applying the same unit cost to all use of a given service (e.g. total GP cost $=$ unit cost of a GP appointment multiplied by number of GP visits) when some variation in unit cost between specific providers is inevitable. Formal cost of surgeries and procedures were not included in estimated cost totals due to lack of a reliable unit costs, but these are not thought significant enough to affect substantively the results reported here. Informal costs derived only from unpaid help provided in performing (I)ADLs and not any other activities, and required the combination of participant-reported answers and the end-of-life interview.

\section{Future research}

International evidence suggests that drivers of high end-of-life care costs include not only clinical need, but also unavailability of appropriate services (e.g. people are admitted to hospital because an adequate homecare service is unavailable) and excessive use of non-beneficial treatment (e.g. high-intensity chemotherapy for a patient with short life expectancy) (Meier, 2011). The data presented in this report therefore raise a series of questions about the relationship between high burden and high utilisation: to what 
extent are high costs a corollary of high need, and to what extent do they reflect a lack of alternative, more cost-effective services?

Notably there is widespread experience of poor health and disability in the last three months of life among TILDA participants, including a high prevalence of modifiable problems. Further research is needed to understand the extent to which these factors, individually and together, impact healthcare service use towards the end of life and the extent to which modifiable factors such as pain and depression can be identified and mitigated to improve quality of life. Given the wide variation in experience, it is important to ascertain the extent to which those in greatest need of services are receiving them, and that all participants are receiving appropriate care.

Also of note, predisposing and enabling characteristics may drive healthcare use and endof-life experience at least as much as medical need. From the data presented while illness burden is a significant driver of usage, other factors such as domestic living situation also have an important effect on healthcare utilisation. Continued consideration must be given not only to improving chronic disease management from prevention and diagnosis to palliative care, but also to understanding the structural and societal factors that determine healthcare access and end-of-life experience in Ireland. The high levels of unmet need we report do not appear linked to socioeconomic factors and the reported lack of awareness of service availability should inform policy focus. 


\section{References}

ANDERSEN, R. M. 1995. Revisiting the behavioral model and access to medical care: does it matter? J Health Soc Behav, 36, 1-10.

BAKITAS, M. \& DIONNE-ODOM, J. N. 2017. When it comes to death, there is no place like home... Or is there? Palliative Medicine, 31, 391-393.

BARRETT, A., SAVVA, G., TIMONEN, V. \& KENNY, R. 2011. Fifty Plus in Ireland 2011: First Results from The Irish Longitudinal Study on Ageing. Dublin.

BEKELMAN, J. E., HALPERN, S. D., BLANKART, C. R., BYNUM, J. P., COHEN, J., FOWLER, R., KAASA, S., KWIETNIEWSKI, L., MELBERG, H. O., ONWUTEAKAPHILIPSEN, B., OOSTERVELD-VLUG, M., PRING, A., SCHREYOGG, J., ULRICH, C. M., VERNE, J., WUNSCH, H. \& EMANUEL, E. J. 2016. Comparison of Site of Death, Health Care Utilization, and Hospital Expenditures for Patients Dying With Cancer in 7 Developed Countries. JAMA, 315, 272-83.

BRICK, A., NORMAND, C., O'HARA, S., CUNNINGHAM, N., DROOG, E., JOHNSTON, B., TYRRELL, E. \& SMITH, S. 2015. Economic Evaluation of Palliative Care in Ireland: Final report [Online]. Trinity College Dublin. Available: http://www.medicine.tcd.ie/health_ policy_management/assets/pdf/Final-report-July-2015.pdf.

CALLIS, N. 2016. Falls prevention: Identification of predictive fall risk factors. Applied Nursing Research, 29, 53-58.

CENTENO, C., LYNCH, T., DONEA, O., ROCAFORT, J. \& CLARK, D. 2013. EAPC Atlas of Palliative Care in Europe. Milan.

CENTRAL STATISTICS OFFICE. 2017. Births, Deaths and Marriages [Online]. Dublin. Available: http://health.gov.ie/publications-research/statistics/statistics-by-topic/causes-ofdeath/. 
DEPARTMENT OF HEALTH. 2017. Age-standardised death rates for selected causes, Ireland, 1999 to 2015 [Online]. Dublin. Available: http://health.gov.ie/publications-research/ statistics/statistics-by-topic/causes-of-death/ [Accessed 2017-09-04.

ECONOMIST INTELLIGENCE UNIT 2015. The Quality of Death Index: Ranking palliative care across the world.

GEORGE, L. K. 2002. Research Design in End-of-Life ResearchState of Science. The Gerontologist, 42, 86-98.

GEORGHIOU, T. \& BARDSLEY, M. 2014. Exploring the cost of care at the end of life. London.

GOLDMAN, L. S., NIELSEN, N. H., CHAMPION, H. C. \& FOR THE COUNCIL ON SCIENTIFIC AFFAIRS, A. M. A. 1999. Awareness, Diagnosis, and Treatment of Depression. Journal of General Internal Medicine, 14, 569-580.

GOMES, B., HIGGINSON, I. J., CALANZANI, N., COHEN, J., DELIENS, L., DAVESON, B. A., BECHINGER-ENGLISH, D., BAUSEWEIN, C., FERREIRA, P. L., TOSCANI, F., MENACA, A., GYSELS, M., CEULEMANS, L., SIMON, S. T., PASMAN, H. R., ALBERS, G., HALL, S., MURTAGH, F. E., HAUGEN, D. F., DOWNING, J., KOFFMAN, J., PETTENATI, F., FINETTI, S., ANTUNES, B. \& HARDING, R. 2012. Preferences for place of death if faced with advanced cancer: a population survey in England, Flanders, Germany, Italy, the Netherlands, Portugal and Spain. Ann Oncol, 23, 2006-15.

INSTITUTE OF MEDICINE 2014. Dying in America: improving quality and honoring individual preferences near the end of life, Washington, DC, The National Academies Press.

KANE, P. M., DAVESON, B. A., RYAN, K., MCQUILLAN, R., HIGGINSON, I. J. \& MURTAGH, F. E. 2015. The need for palliative care in Ireland: a population-based estimate of palliative care using routine mortality data, inclusive of nonmalignant conditions. J Pain Symptom Manage, 49, 726-733.e1.

KATZ, S., FORD, A., MOSKOWITZ, R., JACKSON, B. \& JAFFE, M. 1963. The index of ADL: a standardized measure of biological and psychological function. JAMA, 185, 914919. 
KENNY, R., WHELAN, B., HILARY CRONIN, H., KAMIYA, Y., KEARNEY, P., O'REGAN, C. \& ZIEGEL, M. 2010. The Design of the Irish Longitudinal Study on Ageing. Dublin.

LAWTON, M. P. \& BRODY, E. M. 1969. Assessment of older people: self-maintaining and instrumental activities of daily living. Gerontologist, 9, 179-86.

MCKEOWN, K., HAASE, T., PRATSCHKE, J., TWOMEY, S., DONOVAN, H. \& ENGLING, F. 2010. National Audit of End-of-Life Care in Hospitals in Ireland, 2008/9. Dublin: Irish Hospice Foundation.

MCNAMARA, A., NORMAND, C. \& WHELAN, B. 2013. Patterns and Determinants of Health Care Utilisation in Ireland. Dublin: The Irish Longitudinal Study on Ageing (TILDA).

MEIER, D. E. 2011. Increased access to palliative care and hospice services: opportunities to improve value in health care. Milbank Q, 89, 343-80.

MORRISON, R. S., MEIER, D. E., FISCHBERG, D., MOORE, C., DEGENHOLTZ, H., LITKE, A., MARONEY-GALIN, C. \& SIU, A. L. 2006. Improving the Management of Pain in Hospitalized Adults. Archives of internal medicine, 166, 1033-1039.

NOLAN, A., MA, Y. \& MOORE, P. 2016. Changes in Public Healthcare Entitlement and Healthcare Utilisation among the Older Population in Ireland. Dublin: The Irish Longitudinal Study on Ageing.

STEPTOE, A., BREEZE, E., BANKS, J. \& NAZROO, J. 2013. Cohort profile: the English longitudinal study of ageing. Int J Epidemiol, 42, 1640-8.

TENO, J. M., GOZALO, P. L., BYNUM, J. P., LELAND, N. E., MILLER, S. C., MORDEN, N. E., SCUPP, T., GOODMAN, D. C. \& MOR, V. 2013. Change in end-of-life care for Medicare beneficiaries: site of death, place of care, and health care transitions in 2000, 2005, and 2009. JAMA, 309, 470-7. 